\title{
Influence of the Three Gorges Project on the Water Resource Components of Poyang Lake Watershed: Observations from TRMM and GRACE
}

\author{
Xiaobin Cai, ${ }^{1,2}$ Lian Feng, ${ }^{3}$ Yuxi Wang, ${ }^{3}$ and Xiaoling Chen ${ }^{2,3}$ \\ ${ }^{1}$ Institute of Geodesy and Geophysics, Chinese Academy of Sciences, Wuhan 430077, China \\ ${ }^{2}$ Key Laboratory of Poyang Lake Wetland and Watershed Research, Ministry of Education, Jiangxi Normal University, \\ Nanchang 330022, China \\ ${ }^{3}$ State Key Laboratory of Information Engineering in Surveying, Mapping and Remote Sensing, Wuhan University, \\ Wuhan 430079, China
}

Correspondence should be addressed to Lian Feng; lianfeng619@gmail.com

Received 11 December 2014; Revised 24 March 2015; Accepted 8 April 2015

Academic Editor: Charles Jones

Copyright (c) 2015 Xiaobin Cai et al. This is an open access article distributed under the Creative Commons Attribution License, which permits unrestricted use, distribution, and reproduction in any medium, provided the original work is properly cited.

\begin{abstract}
The Three Gorges Project (TGP) has received many criticisms about its potential effects on the changes in the downstream ecosystems. Poyang Lake is the largest body of water downstream of the TGP, and it is not immune to these changes. TRMM and GRACE data were introduced in this study to estimate river-lake water exchange, from which the hydrological responses of Poyang Lake could be identified. A significant decreasing trend of the runoff coefficient has been observed since 2003 , resulting in $6.02 \mathrm{~km}^{3}$ more water discharge from the lake into the Yangtze River than under normal conditions. No significant interannual changes occurred in the water level or local precipitation, and GRACE observations revealed that groundwater discharge appeared to be the most likely compensation for the water loss. A novel approach, namely, the groundwater abnormality index (GAI), was developed to depict the water exchange using GRACE and surface water observations. Lower than normal GAIs were found between 2003 and 2005, reaching a minimum of -29.26 in October 2003, corresponding to ten times of the mean GAI during 2006-2012, clearly indicating a significant water exchange in Poyang Lake Basin from groundwater to surface water after the TGP impoundment.
\end{abstract}

\section{Introduction}

The hydrological conditions of some of the world's water systems have been disturbed by climate change and/or human activities [1-3], leading to numerous social and ecological problems. A typical example is the Three Gorges Project (TGP) or Three Gorges Dam (TGD) of China, which is constructed in the middle reach of the Yangtze River (see Figure 1(a)). Since the impoundment of the TGP in 2003, the ecosystem of the downstream Yangtze River has been reported to be significantly changed. For example, the operation of the TGP has altered the water and sediment discharges of the downstream Yangtze River in terms of magnitude and temporal distribution [4-6].

Poyang Lake is the largest freshwater lake of China and an important tributary of the Yangtze River downstream of the TGP, where water exchanges constantly between the river and the lake [7]. The unique geographic position and hydrologic conditions of Poyang Lake make it an optimal area to study the downstream influence of the TGP. For example, with hydrological and satellite observations [8], it was reported that $7.86 \mathrm{~km}^{3}$ of water was lost from Poyang Lake after the impoundment of the TGP in 2003. Since then, a decreasing trend has been observed in the inundated area of the lake using long term MODIS observations [9], and this has been further confirmed [10] with higher resolution Landsat TM/ETM+ and hydrological measurements.

Some researchers tried to assess the environmental consequences of the changed hydrological conditions of Poyang Lake. Reference [11] argued that the water level fluctuation in Poyang Lake has been intensified by the TGP, resulting in an altered flow regime in the middle reaches of Yangtze River. The increased fluctuation makes droughts and floods 


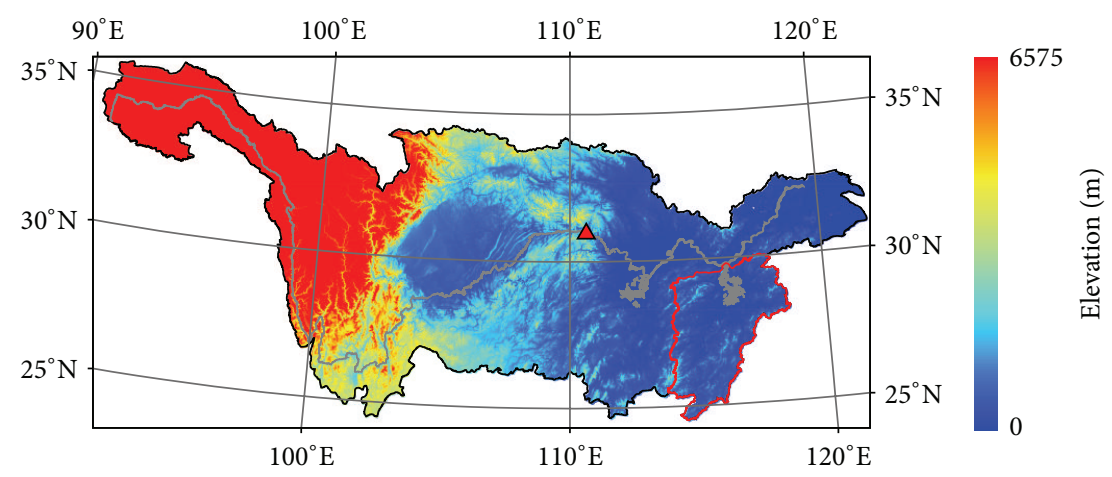
$\Delta$ TGP
Poyang Lake Basin
- Yangtze River

(a)

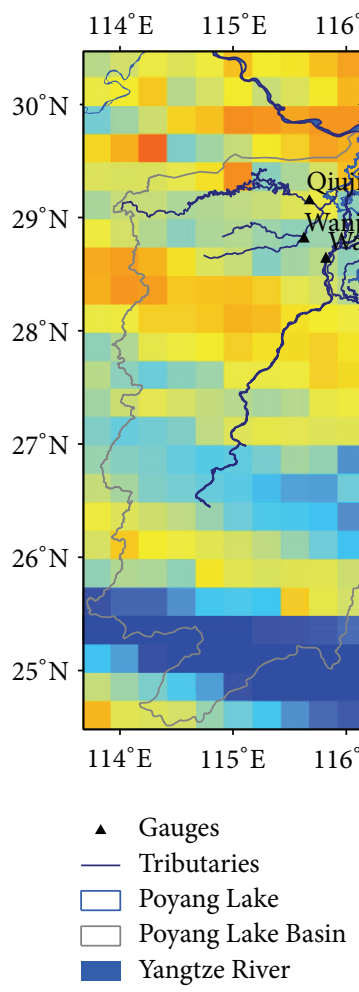

(b)

FIGURE 1: Study area maps. (a) Locations of the TGP and Poyang Lake Basin in the Yangtze River basin; the red triangle is the TGP and the background is SRTM DEM. (b) Major tributaries and gauges in the basin; the average TRMM precipitation during 1998-2012 is shown as background. The black triangles and blue lines annotate the hydrologic stations in the lake and its main tributaries, respectively.

more likely to occur in Poyang Lake [12]. For example, it was demonstrated that the operation of the TGP served as an important driving factor behind the severe drought of Poyang Lake in 2006 [13]. It also has been predicted that releases from Three Gorges Reservoir (TGR) in early summer may increase the water discharge of the Yangtze River, leading to higher flood risk in Poyang Lake [14]. Significant scouring has occurred in Yangtze River due to the modulated water discharges from the TGP, lowering the riverbed and thus increasing the water level difference between the Yangtze River and Poyang Lake [6]. Consequently, more water has drained from the lake into Yangtze River, reducing the inundated area of Poyang Lake and leading to more frequent drought in local regions in recent years [15].

Although satellite observations are an important data source in obtaining the above findings, the only information they have provided is the inundation area of Poyang Lake, leaving the hydrological changes to be primarily revealed through gauged water level and runoff measurements. A potential problem is that exchange between groundwater and surface water appears impossible to be detected with either optical remote sensing or traditional hydrological 
measurements. Until this process can be monitored, changes in Poyang Lake cannot be easily linked to the TGD. Additionally, although there are 15 hydrological stations located in the Poyang Lake region (eight in the lake body and seven others in the lake drainage), such point-based observations have difficulty representing the comprehensive hydrological conditions of the entire drainage basin due to their limited spatial coverage.

Fortunately, the Gravity Recovery and Climate Experiment (GRACE) satellite launched jointly in 2002 by Germany and the USA provides an opportunity to detect the variability of groundwater on a large spatial scale. The timevariable gravity observation from GRACE can be recovered as terrestrial water storage (TWS), which consists of surface water, ice (and snow), the biosphere, soil moisture, and groundwater [16]. With the global land data assimilation systems (GLDAS), the GRACE data have been used widely to monitor TWS and groundwater in large basins with area $>0.2$ million $\mathrm{km}^{2}[15,17-19]$. Moreover, changes in lakes and reservoirs, where the basin area is not so large, can also be detected with GRACE observations [20-23]. Thus, GRACE is introduced in this study to investigate the impact of the TGD on Poyang Lake from the perspective of groundwater exchange.

\section{Study Area}

Poyang Lake is located in eastern China, and it is connected to the Yangtze River in the south (see Figure 1). The lake receives water from five main tributaries (Ganjiang, Fuhe, Xinjiang, Raohe, and Xiushui) and then discharges into Yangtze River at Hukou. With a catchment area of approximately 0.16 million $\mathrm{km}^{2}$, Poyang Lake basin supplies $17 \%$ of the annual total water resource of the Yangtze River basin [10]. The lake is the largest freshwater body in the basin and the average depth is approximately 8.4 meters. The water stored in the lake can cover the Poyang Lake Basin with approximately $17 \mathrm{~cm}$ depth [24]. The inundated area can reach to more than $3000 \mathrm{~km}^{2}$ in flood periods, but it often decreases to less than $1000 \mathrm{~km}^{2}$ in dry periods [9]. The exposed lake bottom during dry seasons forms an important international wetland, serving as the largest winter habitat for migrant birds from Siberia. However, frequently occurred spring droughts in recent years have led to numerous environmental problems in the local regions [25], destroying habitats for various rare birds. As much, there is an urgent need to understand the rapid changes in the water resources of Poyang Lake, which is critical for water conservation in the lake region and in the Yangtze River basin.

\section{Data and Methods}

Three types of data were used in the study, including water level and runoff measurements from gauging stations, TRMM precipitation data and GRACE data. Correlation analysis and a novel approach, the groundwater abnormality index (GAI), were conducted to reveal changes in different water resource components between 2003 and 2012.
Water level data collected at Hukou, the only outlet of Poyang Lake, was used to represent the water volume changes of the lake. The monthly mean water level was derived from daily gauge observations from January 1, 2003, to December 31, 2012. TRMM 3B43 monthly precipitation products between January 1998 and December 2012 were obtained from the NASA website (ftp://disc2.nascom.nasa.gov/data/ s4pa/TRMM_L3/TRMM_3B42). With a spatial resolution of $0.25 * 0.25$ degrees $(\sim 27.5 * 27.5 \mathrm{~km}$ at the equator $)$, TRMM data were integrated over the Poyang Lake Basin to represent its monthly precipitation conditions, whereas annual precipitation was summed from the monthly data. Comparisons between the long term monthly water level and the precipitation data were conducted to check if there are any trends or abrupt changes in the two independent measurements. Monthly runoff from the Poyang Lake Basin was represented by the sum of the five main tributaries of the lake, as no reliable measurement of the lake's outflow could be obtained [8]. The hydrologic stations include Waizhou, Lijiadu, Meigang, Hushan, Dufengkeng, Wanjiabu, and Qiujin (see Figure 1(b)). The annual runoff depth was calculated as the annual runoff volume divided by the area of the Poyang Lake Basin [26]. A runoff coefficient $\left(R_{c}\right)$ based on the ratio of annual precipitation to runoff was introduced to assess the interactions between these two components in a long term fashion [27].

Monthly GRACE TWS equivalent water thickness data were obtained from GRACE Tellus of JPL which were derived from CSR RL05 spherical harmonics to monitor changes in the total water volume $W_{s}$ stored in the basin. The detailed processing methods of TWS products can be found $[28,29]$. Scaling coefficients were applied to the original TWS products for the small spatial scale application of such products [30]. The spatial resolution of TWS products is $1 * 1$ degree $(\sim 111 * 111 \mathrm{~km}$ at the equator $)$. Monthly TWS products from January 2003 to December 2012 were downloaded from the Jet Propulsion Laboratory (JPL) (ftp:// podaac-ftp.jpl.nasa.gov/allData/tellus/L3/land_mass/RL05/) with the absence of five months: June 2003, January 2011, June 2011, May 2012, and October 2012.

Four major water components may exist in the GRACE TWS observations, including groundwater, soil moisture, snow and ice, and surface water [16], whereas only groundwater can quickly exchange with surface water. Thus, the relationship between surface water and TWS should be stable if there is no significant groundwater exchange. The surface water component could be represented using the water level of Poyang Lake $\Delta W_{\text {bsl }}$. The observed total water storage variation $\Delta W_{\text {tws }}$ from GRACE can be regarded as the TWS; the normal estimated water storage variation $\widetilde{\Delta W}_{\text {tws }}$ without significant groundwater exchange is based on the relationship between $\Delta W_{\text {bsl }}$ and $\Delta W_{\text {tws }}$ (shown in (1)). Thus, a groundwater abnormality index (GAI) based on $\Delta W_{\text {bsl }}$ and $\Delta W_{\text {tws }}$ is proposed in this study, which can be used to monitor groundwater exchange:

$$
\begin{aligned}
& \Delta W_{\mathrm{tws}}=A * \Delta W_{\mathrm{bsl}}+B \\
& \mathrm{GAI}=\Delta W_{\mathrm{tws}}-{\widetilde{\Delta W_{\mathrm{tws}}}} .
\end{aligned}
$$




\section{Results}

The monthly mean water level of Poyang Lake fluctuated between $14.47 \mathrm{~m}$ and $19.67 \mathrm{~m}$ during 2003-2012, with the maximum observed in February 2004 and the minimum in July 2010, respectively. Concurrent precipitation in the Poyang Lake Basin varied from $4.02 \mathrm{~mm}$ to $437.14 \mathrm{~mm}$, and the extreme values occurred in Oct $2004(4.02 \mathrm{~mm})$ and in June 2010 (437.14 mm),respectively. Correlation analysis showed that the determination coefficient (e.g., $R^{2}$ ) between water level and precipitation reached a maximum of 0.54 $(P<0.05)$ with two months of lag for the water level. No significant trends or abrupt changes were found for the water level and precipitation during the 10 -year period.

Correlation analysis revealed a tight relationship between the annual precipitation and runoff depth during 1998-2009 with the exception of 2003 (see Figure 3), and the determination coefficient $R^{2}$ reached 0.83 , which is statistically significant $(P<0.05)$. A first order linear fit between precipitation and runoff was established for the data between 1998 and 2009 when the data from 2003 were excluded (see Figure 3). The relationship between annual precipitation $(y)$ and runoff depth $(x)$ of the Poyang Lake drainage can be defined as

$$
y=1.4752 x+1883.2
$$

However, the data point of year 2003 falls far away from the regression line, suggesting an abnormal precipitation-runoff depth relationship for this year. Specifically, the real runoff depth was more than twice that under normal conditions (estimated with (3)), corresponding to an increased water volume of $6.02 \mathrm{~km}^{3}$. However, water storage in the lake was still the third largest during 2003 to 2012 as no abrupt change was found for the water level of Poyang Lake during this period. On the other hand, rapid changes of the runoff coefficient occurred between 1998 and 2009. With a range of $0.29 \sim 0.59$, the runoff coefficient showed a statistically $(P<$ 0.05 ) significant decreasing trend over this period, with the largest value observed in 1998 and the smallest in 2004.

The GRACE-derived TWS data agreed very well with the monthly variations of the lake's water level during the observation period (see Figure 4). The relationship between the monthly TWS and water level could be defined as $\Delta W_{\mathrm{tws}}=3.32 * \Delta W_{\mathrm{bsl}}+2.87$, and the coefficient of determination $R^{2}$ between the two variables reached 0.58 $(P<0.05)$, suggesting that most of the changes in the total water resources of the Poyang Lake drainage basin could be explained by surface water variability. When the groundwater exchange is relatively stable, one meter of water level variation in Poyang Lake corresponds to a TWS change of $3.32 \mathrm{~km}^{3}$. However, significant divergence between the two curves was found during 2003 and 2005, indicating potential changes of the TWS between these years.

To further reveal abnormal features of TWS, Figure 5 plots the monthly GAI between 2003 and 2012. The GAI captures the seasonality well during the overall period, with large values occurring in wet seasons and small values in dry seasons. The most striking observation is that an abrupt

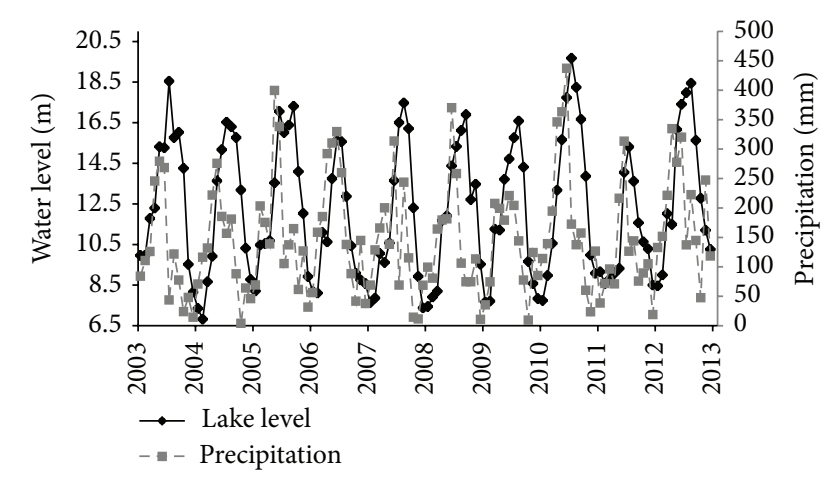

Figure 2: Monthly variations of lake level and precipitation in Poyang Lake Basin during 2003-2012.

decrease occurred in June 2003, and the GAI persisted at a low level through May 2005. The GAI reached a minimum of -29.26 in October 2003, representing $\sim 10$ times the magnitude of the mean GAI between 2006 and 2012 and clearly suggesting rapid groundwater exchange at that time.

\section{Discussion}

TRMM annual precipitation observations showed a rather stable correlation with the runoff in the Poyang Lake drainage basin. However, the relationship between the annual precipitation and runoff depth showed an abrupt change in 2003, after which a significant decreasing trend was found for the runoff coefficient of the lake basin. Then, a natural question would be what could cause such significant hydrological dynamics? The construction of the largest hydroelectric dam in the world, the TGD, is likely to be one of the reasons, as it was impounded just before the abnormality of the runoff in the Poyang Lake region. The impoundment of the TGD reduced the flow into the downstream Yangtze River, increasing the water discharge from Poyang Lake into the Yangtze River and weakening the Yangtze's blocking effect [7]. In addition, the runoff of Poyang Lake increased abnormally in 2003 to $6.02 \mathrm{~km}^{3}$, which is consistent with the MODIS-estimated lake volume decrease $\left(7.86 \mathrm{~km}^{3}\right)$ in June 2003 [8] and on the same order of magnitude as the water impounded in the TGP during the impounding period in that year $\left(\sim 11.56 \mathrm{~km}^{3}\right)$ [22]. The difference between the abnormal runoff increase and the water impounded by the TGP may be due to the water compensation from other great lakes (such as Dongting Lake) or tributaries downstream of the TGD.

The increased runoff caused a significant water resource decrease in the Poyang Lake Basin, but no obvious change could be identified in the water level (see Figure 2). Thus, the water lost from Poyang Lake due to the TGP must be filled by other water sources. Rainfall could serve as one such possible source. However, the interannual changes in the precipitation did not coincide with those of the runoff (Figure 2). Groundwater may be another source that replaces the lost surface water. Although its influence is difficult to assess with the limited in situ measurements, the GRACE observations provide an alternative approach to monitoring 


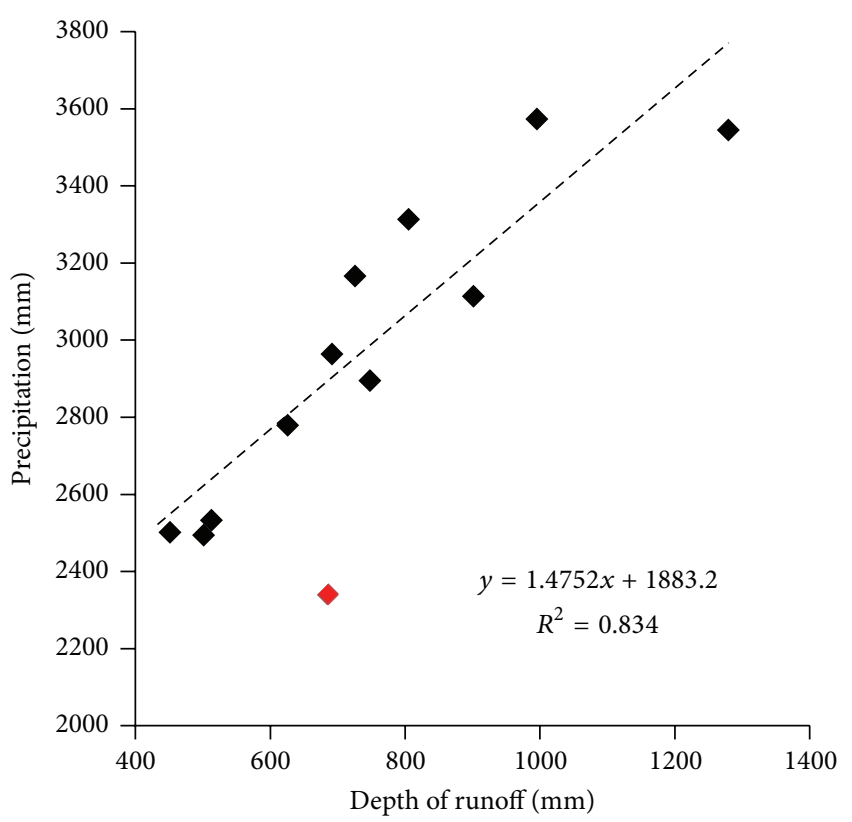

(a)

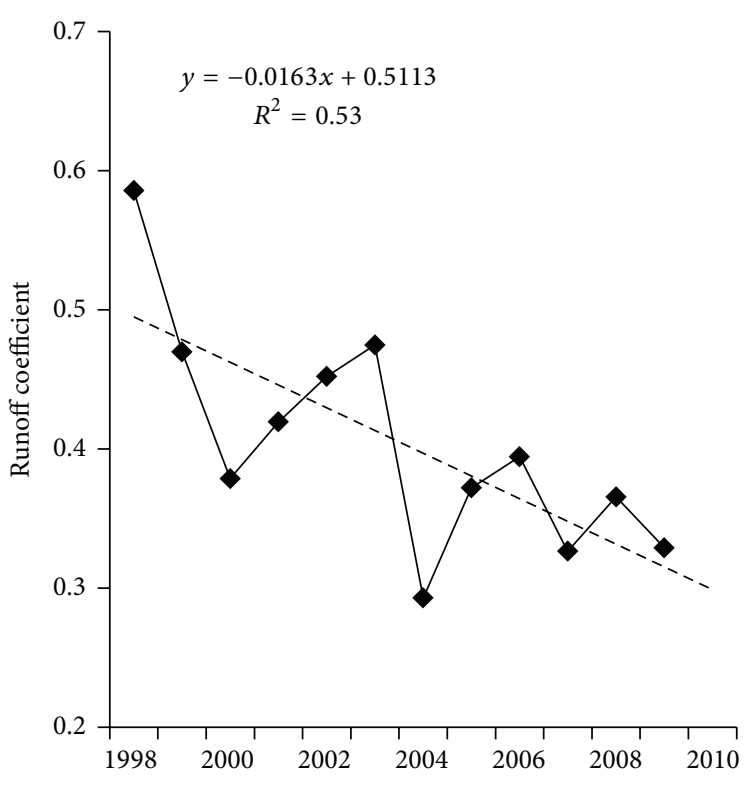

(b)

Figure 3: (a) Correlation between annual precipitation and depth of runoff (the red dot shows the data in 2003). (b) The runoff coefficient of variation during 2003-2009.

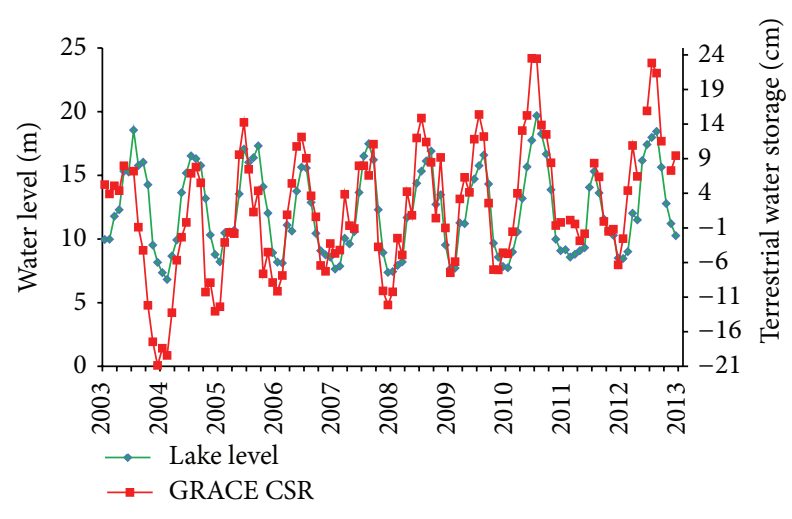

FIGURE 4: Monthly variations of lake level and TWS derived from GRACE CSR between 2003 and 2012.

the groundwater variations in large lake basins such as Poyang Lake. Compared with the surface water variations, the TWS (including groundwater) observations from the satellite showed that an abnormal low period occurred from July 2003 to May 2005. Moreover, the GAI estimates with GRACE and water level measurements also revealed significant exchanges between surface and groundwater in the same period. The low GAI during 2003-2005 indicates that the observed TWS was smaller than that in normal conditions, suggesting that the percentage of groundwater in the TWS was lower to compensate for the surface water in the abnormal period. To our knowledge, this is the first time that the influence of the TGD on the groundwater exchange of Poyang Lake was monitored. This GAI approach enables exchanges between groundwater and surface water to be estimated quantitatively. Note that while the previous study by [31] indicated that the

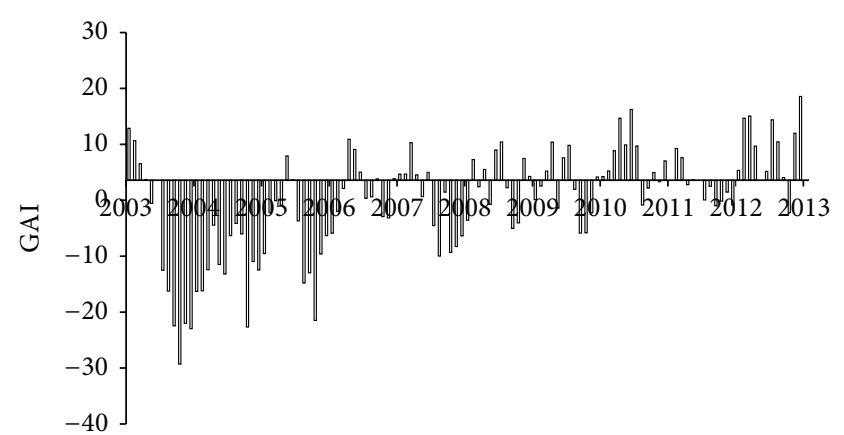

FIGURE 5: Variation of GAI between 2003 and 2012; the $x$-axis is located at the mean of the GAI after 2006.

impoundment of the TGD may lead to seasonal variations of the gauged water level in Poyang Lake, the changes tend to be diminished when an interannual scale is considered in this study.

Could the rapid changes in runoff coefficients and groundwater exchange be a misinterpretation due to the uncertainties of the satellite observations? It has been proven that TRMM has good performance in monthly stream flow simulations in the hydrological model of Poyang Lake [32]. The data were also validated with rain gauge observations and showed excellent agreement in the Poyang Lake Basin [8]. Monthly TRMM data also showed good performance in this study. The coefficient of determination for the correlation analysis between monthly precipitation derived from TRMM and 2-month lagged lake level series was 0.54 in this study. This suggests that rainfall in the Poyang Lake Basin is still the most important factor that impacting the 
surface water variations in Poyang Lake although river-lake exchange constantly occurring. The temporal lag may be because the rainfall in the basin needs about two months to accumulate and then transfer into the lake. Based on water component exchange analysis in Poyang Lake during the TGP impoundment, a significant decreasing trend was found in the runoff coefficients of 1998-2009, especially after 2003, possibly demonstrating that more water from precipitation fed into the groundwater in the latter six years because the same rainfall created less runoff.

The TWS variations information was derived from the gravity field observation of GRACE satellites. However, the gravity field could also be modulated by other resources of mass quality changes. For example, the extensive urbanization processes in the local regions [33] (such as the infrastructure construction) could cause mass transport over the drainage basin. However, this could only lead to mass redistribution within a confined region, and influence on the gravity field of watershed scales is negligible. Severe sand mining could also serve as another factor to the mass changes in Poyang Lake [24]. The sand mined from Poyang Lake is estimated as $448.9 * 10^{12} \mathrm{~g}_{\text {year }}{ }^{-1}$ (equivalent to a volume of 236 million $\mathrm{m}^{3}$ year ${ }^{-1}$ ) by [34] based on the vessels extracted from remotely sensed images. In other words, the sand loss resulted in a $0.28 \mathrm{~cm}_{\text {year }}{ }^{-1}$ TWS reduction for Poyang Lake Basin, which is rather small compared with the water mass variability. Thus, the impact of sand mining in the ten-year analysis of the GRACE observations, if any, should be small.

The GRACE data have been successfully applied in many small areas near reservoirs with obvious surface water variation [21-23], although the data are more recommended for a basin more than 0.2 million $\mathrm{km}^{2}$. The timing of the abnormal GAI variation derived from GRACE observations in Poyang Lake Basin agrees well with that of the TGP impoundment in 2003. This also demonstrates the ability of GRACE to monitor the groundwater of river/lake basins with an area of less than 0.2 million $\mathrm{km}^{2}$. Moreover, the fluctuation patterns of GAI also show the reasonability of the GRACE observations after 2006 as the normal seasonal exchange between groundwater and surface water. The annual periodic variation of the GAI showed that lower GAI often existed in the dry season, suggesting that the groundwater could feed the surface water. In contrast, the flow from surface water to groundwater may exist with higher GAI during flood periods. Based on the aforementioned results from the surface water and TWS observations in Poyang Lake Basin, the GAI showed good performance in explaining the complicated water exchange between groundwater and surface water, especially after the impoundment of the TGP.

\section{Conclusions}

An increase was observed based on the runoff coefficient in 2003, whereas concurrent precipitation did not show a significant abnormality. Based on the relationship between runoff and precipitation, a significant amount of water flowed into the Yangtze River after the impoundment of the TGP in 2003. This suggests that the impoundment of the TGD had an obvious two-year influence on Poyang Lake. Using GRACE observations and a novel index (GAI), the response of the TWS to surface water variations was studied. Results showed that groundwater discharge served as the most likely source to compensate for the surface water.

TWS variations refer to the fluctuations of different components in terms of both surface water and groundwater. However, the hydrological process of the Poyang Lake Basin is extremely complicated as it responds to both the climate scenarios and the land-cover changes $[35,36]$. Only the exchanges between surface water and groundwater were analyzed with the limited data set in this study. Further investigation of independent water resource components is required to reveal the detailed processes of water resources which occurred in the basin.

\section{Conflict of Interests}

The authors have declared that no competing interests exist.

\section{Acknowledgments}

This study was supported by the National Natural Science Foundation of China (41101427, 41331174, and 41401388) and the Key Laboratory of Poyang Lake Wetland and Watershed Research (Jiangxi Normal University), Ministry of Education (JXS-EW-00). The authors thank NASA for providing the TRMM and GRACE data.

\section{References}

[1] J. C. Knox, "Floodplain sedimentation in the Upper Mississippi Valley: natural versus human accelerated," Geomorphology, vol. 79, no. 3-4, pp. 286-310, 2006.

[2] J. P. M. Syvitski, C. J. Vörösmarty, A. J. Kettner, and P. Green, "Impact of humans on the flux of terrestrial sediment to the global coastal ocean," Science, vol. 308, no. 5720, pp. 376-380, 2005.

[3] H. Wang, Z. Yang, Y. Saito, J. P. Liu, X. Sun, and Y. Wang, "Stepwise decreases of the Huanghe (Yellow River) sediment load (1950-2005): impacts of climate change and human activities," Global and Planetary Change, vol. 57, no. 3-4, pp. 331-354, 2007.

[4] X. Chen, Y. Zong, E. Zhang, J. Xu, and S. Li, "Human impacts on the Changjiang (Yangtze) River basin, China, with special reference to the impacts on the dry season water discharges into the sea," Geomorphology, vol. 41, no. 2, pp. 111-123, 2001.

[5] J. Xu, D. Yang, Y. Yi, Z. Lei, J. Chen, and W. Yang, "Spatial and temporal variation of runoff in the Yangtze River basin during the past 40 years," Quaternary International, vol. 186, no. 1, pp. 32-42, 2008.

[6] K. Xu and J. D. Milliman, "Seasonal variations of sediment discharge from the Yangtze River before and after impoundment of the Three Gorges Dam," Geomorphology, vol. 104, no. 3-4, pp. 276-283, 2009.

[7] Q. Hu, S. Feng, H. Guo, G. Chen, and T. Jiang, "Interactions of the Yangtze river flow and hydrologic processes of the Poyang Lake, China," Journal of Hydrology, vol. 347, no. 1-2, pp. 90-100, 2007. 
[8] L. Feng, C. Hu, X. Chen, and R. Li, "Satellite observations make it possible to estimate Poyang Lake's water budget," Environmental Research Letters, vol. 6, Article ID 044023, 2011.

[9] L. Feng, C. Hu, X. Chen, X. Cai, L. Tian, and W. Gan, "Assessment of inundation changes of Poyang Lake using MODIS observations between 2000 and 2010," Remote Sensing of Environment, vol. 121, pp. 80-92, 2012.

[10] Y. Liu, G. Wu, and X. Zhao, "Recent declines in China's largest freshwater lake: trend or regime shift?" Environmental Research Letters, vol. 8, no. 1, Article ID 014010, 2013.

[11] X. Xu, Y. Tan, and G. Yang, "Environmental impact assessments of the Three Gorges Project in China: issues and interventions," Earth-Science Reviews, vol. 124, pp. 115-125, 2013.

[12] X. Li, Q. Zhang, and X. Ye, "Capabilities of satellite-based precipitation to estimate the spatiotemporal variation of flood/ drought class in Poyang Lake basin," Advances in Meteorology, vol. 2013, Article ID 901240, 9 pages, 2013.

[13] Z. Dai, J. Du, J. Li, W. Li, and J. Chen, "Runoff characteristics of the Changjiang River during 2006: effect of extreme drought and the impounding of the Three Gorges Dam," Geophysical Research Letters, vol. 35, no. 7, Article ID L07406, 2008.

[14] T. Nakayama and D. Shankman, "Impact of the Three-Gorges Dam and water transfer project on Changjiang floods," Global and Planetary Change, vol. 100, pp. 38-50, 2013.

[15] W. Feng, M. Zhong, J.-M. Lemoine, R. Biancale, H.-T. Hsu, and J. Xia, "Evaluation of groundwater depletion in North China using the Gravity Recovery and Climate Experiment (GRACE) data and ground-based measurements," Water Resources Research, vol. 49, no. 4, pp. 2110-2118, 2013.

[16] A. Cazenave and J. Chen, "Time-variable gravity from space and present-day mass redistribution in the Earth system," Earth and Planetary Science Letters, vol. 298, no. 3-4, pp. 263-274, 2010.

[17] M. Rodell, I. Velicogna, and J. S. Famiglietti, "Satellite-based estimates of groundwater depletion in India," Nature, vol. 460, no. 7258, pp. 999-1002, 2009.

[18] J. Sheffield, C. R. Ferguson, T. J. Troy, E. F. Wood, and M. F. McCabe, "Closing the terrestrial water budget from satellite remote sensing," Geophysical Research Letters, vol. 36, no. 7, Article ID L07403, 2009.

[19] P. J.-F. Yeh, S. C. Swenson, J. S. Famiglietti, and M. Rodell, "Remote sensing of groundwater storage changes in Illinois using the Gravity Recovery and Climate Experiment (GRACE)," Water Resources Research, vol. 42, no. 12, Article ID W12203, 2006.

[20] J. L. Awange, M. A. Sharifi, G. Ogonda, J. Wickert, E. W. Grafarend, and M. A. Omulo, "The falling lake Victoria water level: GRACE, TRIMM and CHAMP satellite analysis of the lake basin," Water Resources Management, vol. 22, no. 7, pp. 775796, 2008.

[21] H. S. Wang, Z. Y. Wang, X. D. Yuan, P. Wu, and E. Rangelova, "Water storage changes in Three Gorges water systems area inferred from GRACE time-variable gravity data," Chinese Journal of Geophysics (Chinese Edition), vol. 50, no. 3, pp. 730736, 2007.

[22] X. W. Wang, C. de Linage, J. Famiglietti, and C. S. Zender, "Gravity Recovery and Climate Experiment (GRACE) detection of water storage changes in the Three Gorges Reservoir of China and comparison with in situ measurements," Water Resources Research, vol. 47, no. 12, Article ID W12502, 2011.

[23] J. G. Zhan and Y. Wang, "Detect water storage variation of Longtan Reservoir with GRACE data," Chinese Journal of Geophysics-Chinese Edition, vol. 54, pp. 1187-1192, 2011.
[24] L. Feng, C. Hu, X. Chen, L. Tian, and L. Chen, "Human induced turbidity changes in Poyang Lake between 2000 and 2010: observations from MODIS," Journal of Geophysical Research C: Oceans, vol. 117, no. 7, 2012.

[25] L. Feng, C. Hu, and X. Chen, "Satellites capture the drought severity around China's largest freshwater lake," IEEE Journal of Selected Topics in Applied Earth Observations and Remote Sensing, vol. 5, no. 4, pp. 1266-1271, 2012.

[26] B. Barthès and E. Roose, "Aggregate stability as an indicator of soil susceptibility to runoff and erosion; validation at several levels," Catena, vol. 47, no. 2, pp. 133-149, 2002.

[27] H. Guo, B. Su, Y. Wang, and T. Jiang, "Runoff coefficients change and the analysis of the relationship between climate factors and runoff coefficients in Poyang Lake Basin (China): 1955-2002," Journal of Lake Sciences, vol. 19, pp. 163-169, 2007.

[28] M. Cheng and B. D. Tapley, "Variations in the Earth's oblateness during the past 28 years," Journal of Geophysical Research B: Solid Earth, vol. 109, no. B9, 2004.

[29] S. Swenson, D. Chambers, and J. Wahr, "Estimating geocenter variations from a combination of GRACE and ocean model output," Journal of Geophysical Research B: Solid Earth, vol. 113, no. 8, 2008.

[30] F. W. Landerer and S. C. Swenson, "Accuracy of scaled GRACE terrestrial water storage estimates," Water Resources Research, vol. 48, no. 4, Article ID W04531, 2012.

[31] H. Guo, Q. Hu, Q. Zhang, and S. Feng, "Effects of the three gorges dam on yangtze river flow and river interaction with poyang lake, China: 2003-2008," Journal of Hydrology, vol. 416417, pp. 19-27, 2012.

[32] X.-H. Li, Q. Zhang, and C.-Y. Xu, "Suitability of the TRMM satellite rainfalls in driving a distributed hydrological model for water balance computations in Xinjiang catchment, Poyang lake basin," Journal of Hydrology, vol. 426-427, pp. 28-38, 2012.

[33] D. Ding and X. Tan, "Numerical simulation of the effects of the urbanization on the Poyang wetland," in Proceedings of the Watershed Management Conference 2010: Innovations in Watershed Management under Land Use and Climate Change, pp. 443-448, ASCE, August 2010.

[34] J. de Leeuw, D. Shankman, G. Wu et al., "Strategic assessment of the magnitude and impacts of sand mining in Poyang Lake, China," Regional Environmental Change, vol. 10, no. 2, pp. 95102, 2010.

[35] H. Guo, Q. Hu, and T. Jiang, "Annual and seasonal streamflow responses to climate and land-cover changes in the Poyang Lake basin, China," Journal of Hydrology, vol. 355, no. 1-4, pp. 106122, 2008.

[36] X. Ye, Q. Zhang, J. Liu, X. Li, and C.-Y. Xu, “Distinguishing the relative impacts of climate change and human activities on variation of streamflow in the Poyang Lake Catchment, China," Journal of Hydrology, vol. 494, pp. 83-95, 2013. 

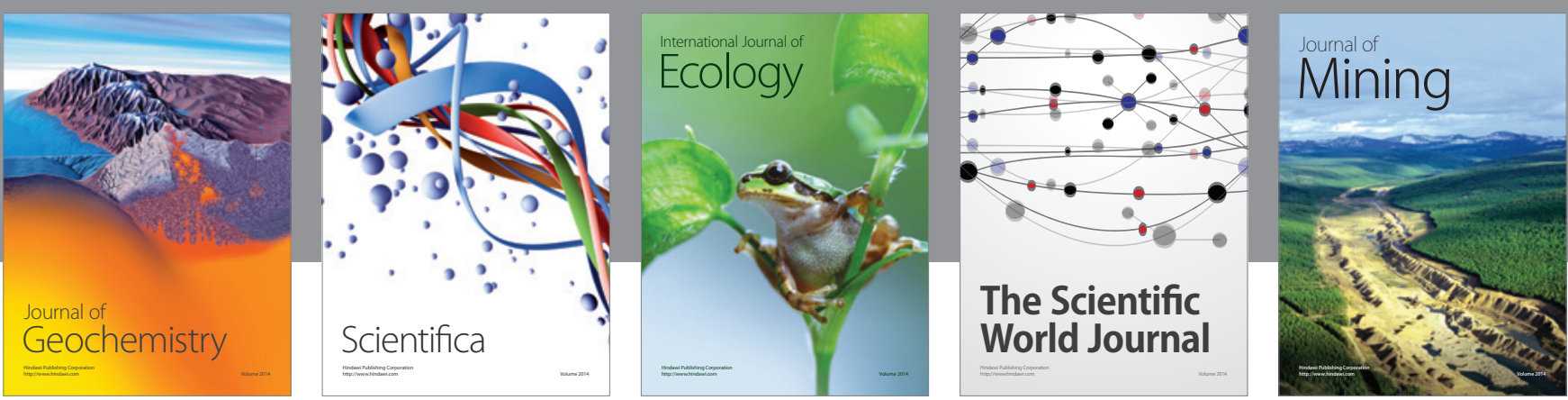

The Scientific World Journal
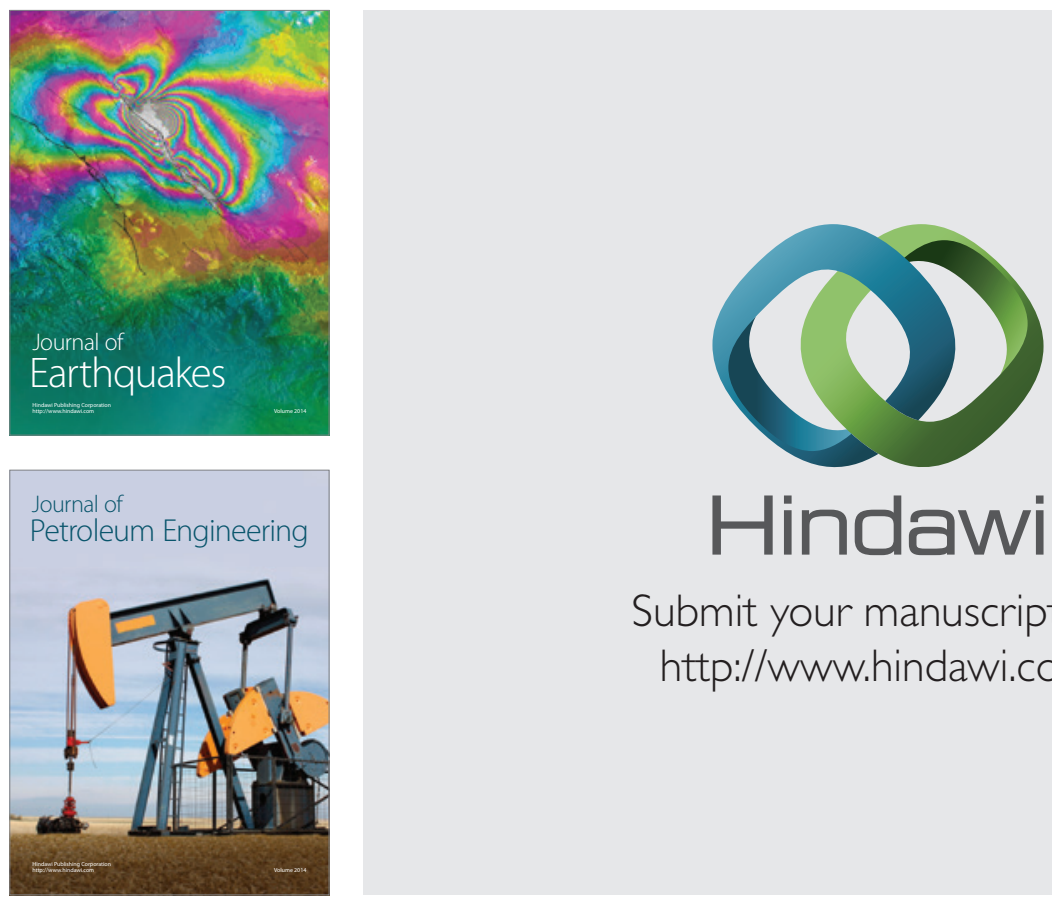

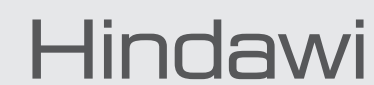

Submit your manuscripts at

http://www.hindawi.com
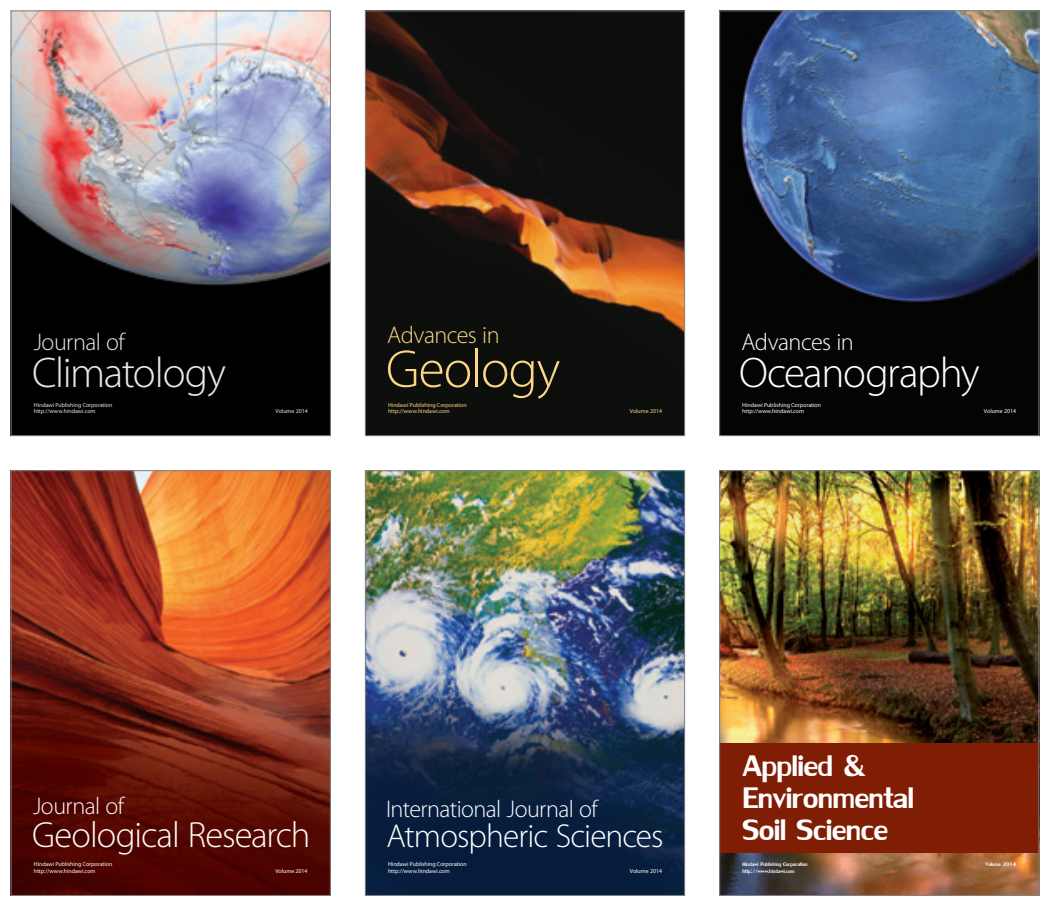
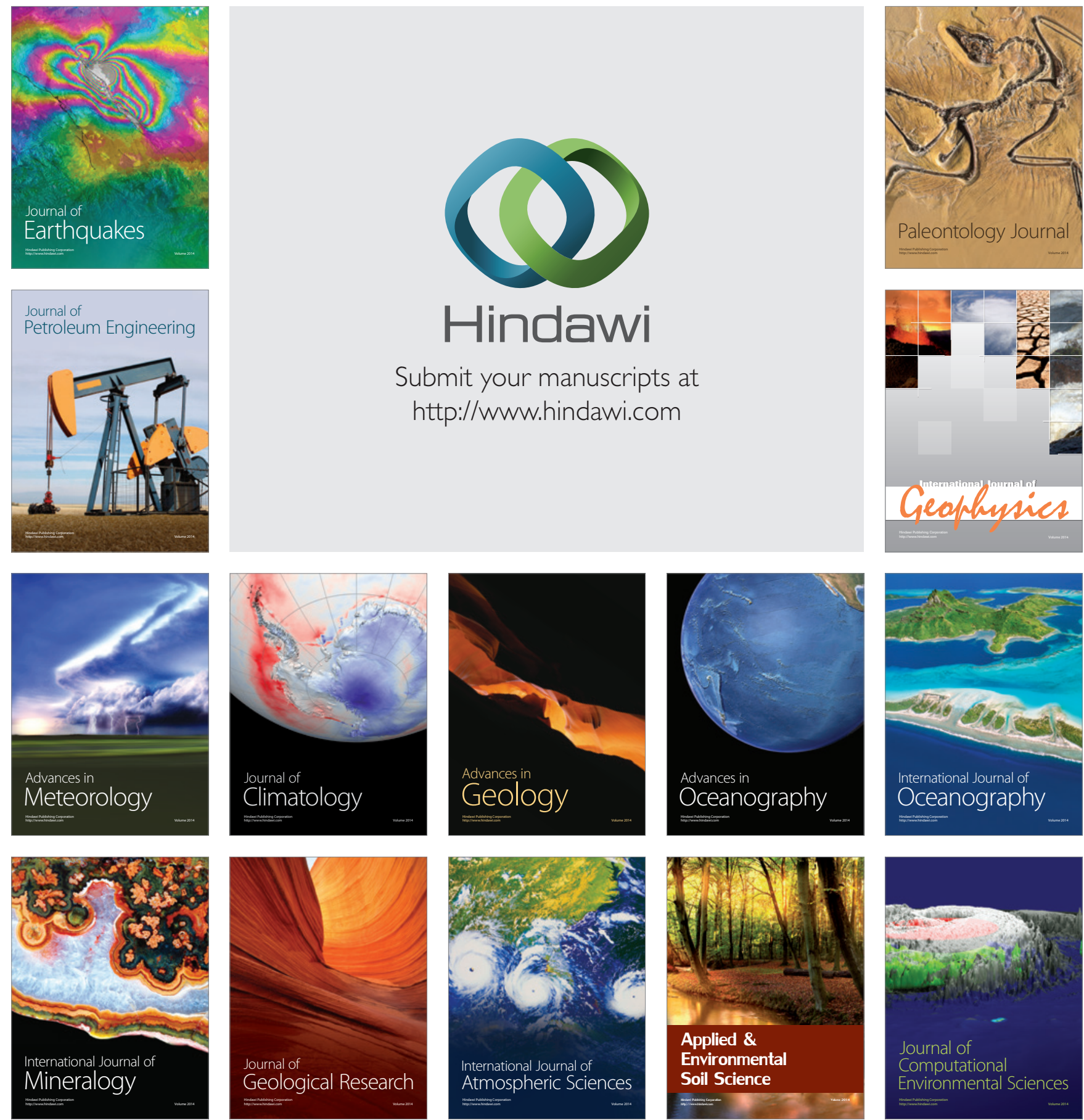